\title{
Expression of cutaneous fatty acid-binding protein (C-FABP) in prostate cancer: Potential prognostic marker and target for tumourigenicity-suppression
}

\author{
ELWIN A. MORGAN ${ }^{1}$, SHIVA S. FOROOTAN ${ }^{1}$, JANET ADAMSON ${ }^{1}$, CHRISTOPHER S. FOSTER $^{1}$, \\ HIROSHI FUJII ${ }^{2}$, MICHIHIRO IGARASHI ${ }^{2}$, CAROL BEESLEY ${ }^{1}$, PAUL H. SMITH ${ }^{1}$ and YOUQIANG KE ${ }^{1}$ \\ ${ }^{1}$ Molecular Pathology Laboratory, School of Cancer Studies, Faculty of Medicine, The University of Liverpool, \\ Liverpool, L69 3GA, UK; ${ }^{2}$ Department of Signal Transduction Research, Niigata University, \\ Graduate School of Medicine and Dental Sciences, 1-757 Asahimachi, Niigata 951-8510, Japan
}

Received November 20, 2007; Accepted December 31, 2007

\begin{abstract}
C-FABP or E-FABP is a metastasis inducing gene over expressed in human prostate carcinomas. To study its prognostic significance, an archival set of prostate tissues was analysed immunohistochemically. Levels of both nuclear and cytoplasmic C-FABP expression in carcinoma cells were significantly higher than those in normal and $\mathrm{BPH}$ tissues and the increased C-FABP was significantly associated with a reduced patient survival time. To test the therapeutic potential of targeting C-FABP, a clone ( $\mathrm{Si}$-clone-2) of cells was established by interfering C-FABP expression in highly malignant PC-3M cells. Suppression of C-FABP in cancer cells significantly inhibited their proliferation and tumourigenicity in vitro. When Si-clone-2 cells were orthotopically implanted into the prostate gland of mouse, 2/13 mice produced primary tumours with an average size of $23 \pm 5 \mathrm{mg}$, and no metastasis was produced in any of the 13 animals. Whereas in the control group, all 14 mice produced primary tumours with an average size of $1450 \pm 370 \mathrm{mg}$ and 9/14 (64.3\%) produced metastasis. When inoculated subcutaneously, all 5 mice inoculated with control cells developed tumours from day 4 , with an average size of $1471 \pm 544 \mathrm{~mm}^{3}$ at 5 weeks after the inoculation; whereas Si-clone- 2 cells produced no tumours in any of the 5 animals at any time-point, indicating the suppression occurred at the initiation stage. Our results suggest that C-FABP may be used as a potential prognostic marker to predict patient outcome and the increased C-FABP
\end{abstract}

Correspondence to: Professor Y. Ke, Molecular Pathology Laboratory, School of Cancer Studies, Faculty of Medicine, The University of Liverpool, 5/6 Floor, Duncan Building, Daulby Street, Liverpool L69 3GA, UK

E-mail: yqk@liverpool.ac.uk

Key words: C-FABP, prognosis, RNAi, prostate cancer, orthotopic implantation, malignant progression expression is a possible target to inhibit the malignant progression of prostate cancer cells.

\section{Introduction}

Prostate cancer is an important male disease in the developed world and more than 30,000 men died each year from this cancer in USA alone $(1,2)$. Like other cancerous diseases, the causes for the development and metastasis of prostate cancer may involve many complicated molecular events, including the increased activities of cancer-promoting genes and the diminished activities of cancer-suppressing genes $(3,4)$. Thus, suppression or promotion of expression of the cancer-related genes may provide an effective way to interfere with the malignant progression of cancer cells. Using several differential display (5)-derived molecular approaches (6-8) combined with a 'subtractive selection' strategy, we have identified and characterised several genes $(9,10)$ whose altered expression may contribute to the initiation and development of prostate cancer. One of such genes involved in malignant progression of cancer cells (11) is that coding for human cutaneous fatty acid-binding protein (C-FABP) which is also called $\mathrm{E}$ (epidemic)-FABP or PA(psoriasis-associated)-FABP, and was originally identified in human skin (12).

In our previous work, it was demonstrated that C-FABP was over-expressed in human prostate cancer cell lines and in most of the prostate carcinoma tissues. When C-FABP gene was transfected into the benign Rama 37 model cells (13), it could promote the growth of primary tumours and induce malignant dissemination $(14,15)$. It was also demonstrated that C-FABP induced metastasis through up-regulation of other oncogenes such as vascular endothelial growth factor (VEGF) $(15,16)$. Although the role of C-FABP in malignant progression of prostate cancer cells had been characterised and confirmed, the possibility to use the increased expression of C-FABP as a prognostic factor was not explored. The therapeutic potential of targeting the over-expressed C-FABP in the highly malignant prostate cancer cells was not previously investigated.

In this work, we have carefully analysed the expression status of C-FABP in an archival set of human prostate tissues 
with patient-following up data and assessed the relationship between the increased C-FABP expression in carcinoma tissues and the length of patient survival time. We have also related the elevated expression levels of C-FABP with the increased joint Gleason scores (GS). To test the therapeutic potential, we have suppressed the expression of C-FABP in the highly malignant prostate cancer cell line PC-3M (17) by RNA interference (RNAi) $(18,19)$ to investigate whether suppression of C-FABP expression can inhibit the onset and the development of primary tumours and their ability to metastasize to secondary sites in mouse.

\section{Materials and methods}

Tissue samples and patients' data. Human prostate tissues comprised an archival set with follow-up data held within the diagnostic archive in the Department of Pathology, University of Liverpool, UK. The patients who died from causes other than metastatic prostate cancer have been excluded from this study. Tissues were taken from 70 prostate adenocarcinoma patients with an average age of 73 years and from 35 benign prostatic hyperplasia (BPH) patients with an average age of 67.5 years who were treated by trans-urethral resection of prostate (TURP) in the Royal Liverpool University Hospital during the 5-year period of 1995-2000. The 7 normal prostate tissues were taken from road accident victims with an average age of 48 years who did not have a history of prostatic disease. This study was approved by Liverpool Local Science Ethics Committee in accordance with the Medical Research Council guidelines (project reference no.: Ke: 02/019). Tissue sections were examined independently by two observers and classified as normal, BPH, and carcinomas. The carcinomas were further classified according to their combined GS (20).

Histological and immunohistochemical staining of tissues. Formalin-fixed tissues were processed and embedded in paraffin wax. Histological sections $(4-\mu \mathrm{m})$ were cut and mounted onto slides as described previously (21). The tissue sections were incubated at $37^{\circ} \mathrm{C}$ overnight prior to staining with haematoxylin and eosin using an automated Varistain 24-4 machine (Thermo Scientific, USA). Immunohistochemical staining for detection of C-FABP was performed in a similar way as that described previously (22). Mounted paraffin tissues were deparaffinised and rehydrated in xylene and ethanol respectively, incubated for $12 \mathrm{~min}$ in methanol and $3 \%$ hydrogen peroxide before being washed. Antigen retrieval for C-FABP (Iwaki Glass Corp., Niigata, Japan) was performed by microwaving at full power for $15 \mathrm{~min}$ in $10-\mathrm{mM}$ sodium citrate buffer. Slides were incubated to anti-human C-FABP serum at a dilution of 1:500. Bound antibodies in each condition were detected by 30 -min incubation with a labelled horseradish peroxidase polymer with an Envision System kit (Dakocytomation, Ely, UK), and visualised by a 10-min exposure to $100 \mu 1$ of 3,3' Diaminobenzidine (DAB). The slides were counter-stained with haematoxylin solution and mounted with DPX synthetic resin. The staining of C-FABP was classified according to both the intensities of staining and the percentages of the cells stained, as described previously (22). The cases were divided into negative or unstained (-) and positively stained. The later was further divided into weakly $(+)$, moderately $(++)$ and strongly $(+++)$ positive.

Cell lines and cell culture conditions. The human prostate cancer cell line used in this work was the highly malignant, metastatic cell line PC-3M, which was derived from the most malignant subpopulation of the prostate cancer cell line PC-3 (23). The cells were cultured and maintained in monolayer in RPMI-1640 (Life Technologies, Paisley, Scotland) and supplemented with $10 \%(\mathrm{v} / \mathrm{v})$ fetal calf serum (Labtech International, UK), hydrocortisone and testosterone $(50 \mathrm{ng} / \mathrm{ml})$ (Sigma, Gillingham, UK), penicillin (100 U/ml) and streptomycin $(100 \mathrm{mg} / \mathrm{ml})$ (Life Technologies). The siRNA transfectant clones originating from PC-3M cells were cultured and maintained with $0.5 \mathrm{mg} / \mathrm{ml}$ geneticin G418 (Life Technologies).

Designing RNA interference molecule to silence C-FABP. A unique 19nt sequence (ACTCAGACTGTCTGCAACT) located towards the end of the 5-prime of C-FABP gene was chosen as the siRNA target site, using the method described on the biotech company Ambion (Cambridgeshire, UK) website (www.ambion.com). This site was immediately downstream from an AA dinucleotide sequence. The uniqueness of the 19nt sequence was confirmed by running the chosen sequence in a blast search to ensure there was no significant sequence homology towards other human or mouse sequences. The silencing construct consisted of 2 complementary oligonucleotides orientated in sense and antisense directions. The 2 DNA strands were the same 19 nucleotide sequence in sense (5'-ACTCAGACTGTCTGCAACTTTCAAGAG AAGTTGCAGACAGTCTGAGTTTTTT-3') and antisense orientations separated by a 9 nucleotide loop sequence (TTCAAGAGA) in the middle and capped at the 3'-end with a poly $\mathrm{T}$ termination sequence. This short DNA molecule was flanked at the 5'-end by a poly A termination sequence preceded by an EcoRI restriction enzyme sequence. The 3 '-end of the antisense strand was capped by an ApaI restriction sequence. The short DNA was commercially synthesised (Invitrogen Life Technologies, Strathclyde, UK) and purchased as two separate oligonucleotides. The sense and antisense strands were annealed together to form a short double stranded DNA molecule which was then ligated to a pSilencer 1.0 U6 plasmid (Ambion, Cambridgeshire, UK) the EcoRI and ApaI sites, and amplified by molecular cloning and transforming into $E$. coli (DH5- $\alpha$ ) cells. The orientation of the insert was confirmed by automated DNA sequencing using an internal pSilencer 1.0 U6 T3 generic sequence primer (5'-ATTAACC CTCAGTAAAGGGA-3').

Transfection of siRNA C-FABP silencing construct. The SiRNA-C-FABP silencing construct was transfected into PC-3M cells by calcium phosphate co-precipitation technique as described previously $(24,25)$. Exponentially growing PC-3M cells were seeded in 2 Petri dishes $(9 \mathrm{~cm}$ in diameter) at a density of $0.5 \times 10^{6} / \mathrm{dish}$. One dish was co-transfected with $10 \mu \mathrm{g}$ pSV2neo plasmid DNA plus $10 \mu \mathrm{g}$ pSilencer plasmid DNA to form a pool of control transfectants; the other dish was co-transfected with $18 \mu \mathrm{g}$ siRNA silencing construct DNA plus $2 \mu \mathrm{g}$ pSV2-neo DNA to generate C-FABP suppressed 
clones. Cells were passaged at a 1:10 ratio, and transfected cells were selected by supplementation of RPMI-1640 medium with $0.5 \mathrm{mg} / \mathrm{ml}$ geneticin G418 (Invitrogen, Paisley, UK); the medium was replaced every 3-4 days. When cell colonies had grown to approximately $3 \mathrm{~mm}$ in size, they were isolated by ring-cloning. Five colonies were isolated for selections of lowest C-FABP expressor. In a separate transfection, a pool of control transfectants was generated.

Detection of protein expression in cultured cells. The expression of C-FABP at protein level in cultured cells was detected by Western blot analysis using an ECL detection system as described previously (26). Total cellular protein was extracted from different cell lines with 2X SDS lysis buffer. Proteins were separated by SDS-PAGE in $10 \%$ acrylamide gel, and transferred onto a nitrocellulose membrane (Hybond ECL, Amersham Pharmacia, Amersham, UK). Primary antibody immunoblotting was performed on proteins using rabbit anti-human C-FABP (Iwaki Glass Corp.) at 1:200 dilution, followed by horseradish peroxidase-conjugated swine antirabbit IgG (Dako) diluted at 1:1000. The protein bands were visualized by exposure to Kodak XAR-5 film and quantified by measuring the intensity of the peak areas using Alpha Imager 2000 densitometer (Alpha Innotech, Cannock, UK). Constitutively expressed actin protein was detected to correct possible loading errors.

Proliferation assay of siRNA transfectants. Effect of suppressed C-FABP expression on cellular proliferation was measured by a proliferation assay. The lowest C-FABP expressor (Si-clone-2), two moderate C-FABP expressors (Si-clone-3 and Si-clone-4), and the control transfectants were cultured for $24 \mathrm{~h}$ in RPMI-1640 medium supplemented with $4 \%(\mathrm{v} / \mathrm{v})$ fetal calf serum, penicillin $(100 \mathrm{U} / \mathrm{ml})$ and streptomycin $(100 \mathrm{mg} / \mathrm{ml})$ under $5 \% \mathrm{CO}_{2}$ at $37^{\circ} \mathrm{C}$. Exponentially growing cells from each culture were seeded in 7 triplicates at a density of $10^{\times 3} / \mathrm{ml} /$ well in 24 -well plate. On each of the 6 experimental days, $200 \mu \mathrm{l}(1 \mathrm{mg} / \mathrm{ml})$ of 3-(4,5-dimethyl thiazol-2-yl)-2,5-diphenyl tetrazolium bromide (MTT) (Sigma-Aldrich, UK) was added to each well and incubated with the cells for $4 \mathrm{~h}$ to form formazan crystals. After the removal of the medium, the formazan crystals were dissolved by the addition of $400 \mu 1$ of dimethyl sulphoxide (DMSO) at $37^{\circ} \mathrm{C}$. Aliquots of $200 \mu \mathrm{l}$ from each well were plated in duplicate in a 96-well micro-titre plate and the optical absorbance was measured in Multiskan MS (Lab Systems Multiskan MS, Finland) plate reader using a 570-nm filter. Optical absorbance values were compared with serially-diluted standard curves of different cell lines using regression analysis to convert the optical absorbance values into cell numbers.

Soft agar assay for tumourigenicity. The tumourigenicity of Si-clone-2, Si-clone-3, Si-clone-4, and the control transfectants was measured by a soft agar assay (27) to test their ability to form colonies. To perform this assay, the bottom of each well in a 6-well plate was cast (at $4^{\circ} \mathrm{C}$ ) with a basement gel layer ( $1 \mathrm{ml}$ for each well) which consisted of a mixture of $3 \mathrm{ml}$ low melting agarose (LMA) gel (2\% LMA in Tris-acetate buffer) and $3 \mathrm{ml}$ of RPMI-1640 medium. The cultured cells were harvested and suspended in the same LMA-RPMI mixture at room temperature at a density of $5 \times 10^{3}$ cells $/ \mathrm{ml}$. The mixture with cells $(2 \mathrm{ml})$ was then poured onto the top of the preset basement gel layer and incubated at $4^{\circ} \mathrm{C}$ for solidification. Once set, the cells in the plates were incubated at $37^{\circ} \mathrm{C}$ under $5 \% \mathrm{CO}_{2}$ for 6 weeks. The colonies developed in each well were counted and the tumourigenicity of each cell line was decided by the number of colonies formed in LMA-RPMI mixture within the 6-week experimental period.

Nude mouse assay. To test for tumourigenicity and metastasis, Si-clone-2 and the control transfectants were orthotopically implanted (28) into the prostate gland of mouse. Fourteen mice were implanted with Si-clone- 2 and control cells, respectively, into the dorso-lateral lobe of prostate gland of the immuno-incompetent CD-1 nude mice (Harlan, UK) at a density of $2 \times 10^{6}$ cells $/ 20 \mu 1 \mathrm{PBS}$. To implant the cells, each mouse was administered with $0.2 \mathrm{mg} / \mathrm{kg} / \mathrm{s} / \mathrm{c}$ Buprenorphine (temgesic) analgesia, and anaesthetised using gas induction at $50 \% / 50 \%$ oxygen/nitrous oxide with $1-2 \%$ isoflurane and oxygen, and nitrous oxide anaesthetic gas. Mice were placed in the supine position, swabbed with iodine around the abdomen, hindquarters and genital area. A midline incision was made in the lower abdomen. Using the bladder as orientation, the dorso-lateral lobe of the mouse prostate gland was identified for implantation of control and Si-clone- 2 cells. Following injection of cells, the surgical wound was sutured using single stitch sutures and the animals monitored post-operatively for loss of appetite, poor grooming or general malaise. Mice were sacrificed 5 weeks after inoculation. At autopsy, primary tumours (where available) were dissected along with the lungs, liver, heart, lymph nodes and other organs of each mouse. Each primary tumour was weighed before fixation in $10 \%$ formalin for a period of $24 \mathrm{~h}$. To find out at what point the suppression activity starts, Si-clone- 2 and control transfectant cells were inoculated subcutaneously into the shoulder region of nude mice at a density of $2 \times 10^{6}$ in $0.2 \mathrm{ml}$ of PBS. The growth of tumour at the site of inoculation was measured weekly over a period of 5 weeks. Measurements of tumour volume was calculated by the formula of: Length $x$ Width $x$ Height $x 0.5236$ (29). All animal experiments were conducted under UKCCCR guidelines with Home Office Project Licence PPL 40/2270 to Professor Y. Ke.

Statistical analysis. Correlation between C-FABP staining and the nature of prostate tissues (normal, benign or malignant) was assessed by 2 -sided Fisher's exact test and $\chi^{2}$ analysis, using the Statistical Package for Social Sciences, Version 14.0 (SPSS Inc., Chicago, IL, USA). Association between $\mathrm{C}-\mathrm{FABP}$ staining and GS of carcinomas was assessed by $\chi^{2}$ test. Correlation between the increased C-FABP staining and the length of prostate cancer patient survival were evaluated using Kaplan-Meier analysis. Differences between patients' groups were assessed by log-rank test. Statistical significance was defined as $\mathrm{p}<0.05$.

\section{Results}

$C$-FABP expression in prostate tissues. Results of immunohistochemical staining for C-FABP in prostate tissues are shown in Table I. Neither cytoplasmic nor nuclear staining 
Table I. CFABP cytoplasmic and nuclear expression in normal, benign and malignant human prostate.

\begin{tabular}{|c|c|c|c|c|c|c|c|c|c|}
\hline \multirow[b]{2}{*}{ Tissue } & \multicolumn{4}{|c|}{$\begin{array}{c}\text { Cytoplasmic } \\
\text { Stain intensities }\end{array}$} & \multirow[b]{2}{*}{ No. of cases } & \multicolumn{4}{|c|}{$\begin{array}{c}\text { Nuclear } \\
\text { Stain intensities }\end{array}$} \\
\hline & - & + & ++ & +++ & & - & + & ++ & +++ \\
\hline Normal & 7 & 0 & 0 & 0 & 7 & 7 & 0 & 0 & 0 \\
\hline $\mathrm{BPH}$ & 33 & 2 & 0 & 0 & 35 & 20 & 7 & 5 & 3 \\
\hline Carcinomas & & & & & & & & & \\
\hline (total) & 3 & 18 & 39 & 10 & 70 & 11 & 14 & 22 & 23 \\
\hline Scores $^{a} \leq 5$ & 3 & 5 & 3 & 1 & 12 & 1 & 3 & 3 & 5 \\
\hline Scores $^{\mathrm{a}}$ 6-7 & 0 & 13 & 18 & 3 & 34 & 7 & 6 & 11 & 10 \\
\hline Scores $^{\mathrm{a}} 8-10$ & 0 & 0 & 18 & 6 & 24 & 3 & 5 & 8 & 8 \\
\hline
\end{tabular}

${ }^{a}$ Combined Gleason scores.
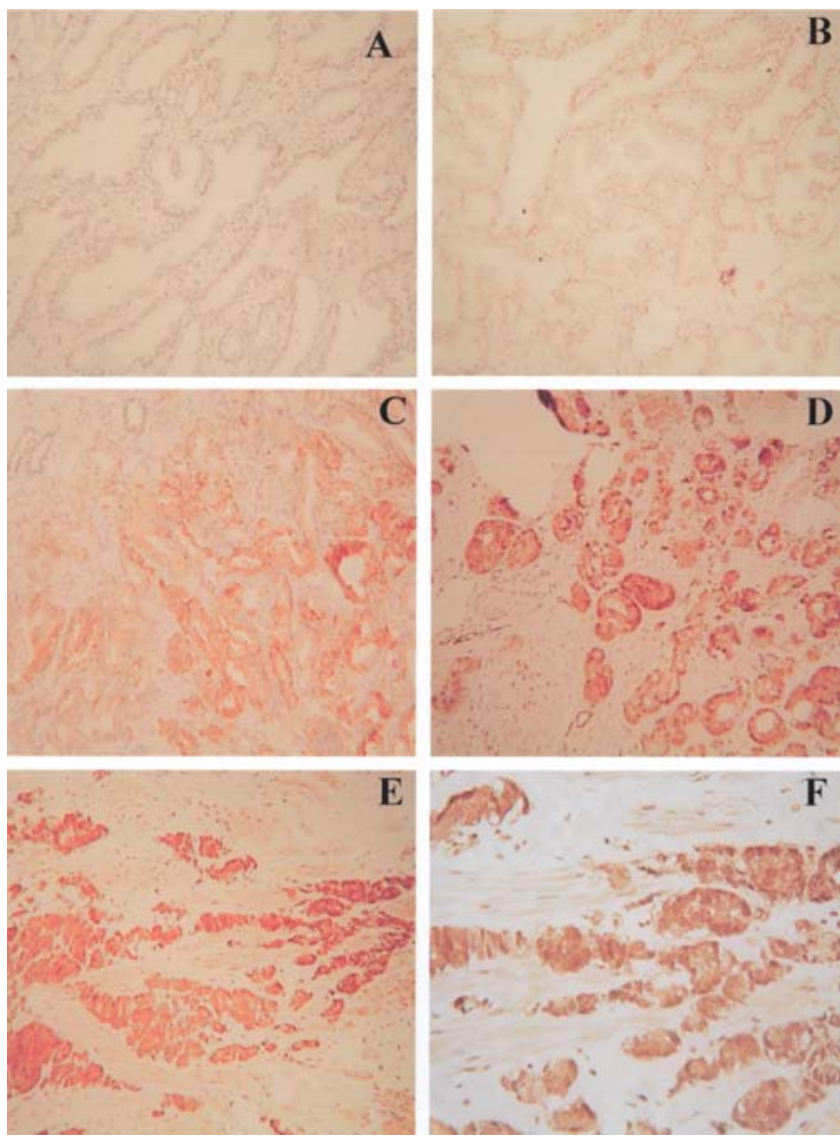

Figure 1. Detection of C-FABP expression in normal, benign and malignant prostate tissues by immunohistochemical staining (magnification is shown in brackets). A, Unstained normal prostate tissue (x100). B, An unstained BPH sample (x100). C, A carcinoma with GS 5 stained weakly to moderately positive (x100). D, A carcinoma with GS 7 stained strongly positive (x100). E, A carcinoma with GS 10 stained strongly positive (x100). F, Strongly positive stain in a carcinoma was observed in both cytoplasm and nucleus (x250).

was observed in any of the 7 normal prostate tissues. The expression of $\mathrm{C}-\mathrm{FABP}$ in $\mathrm{BPH}$ and carcinoma tissues was detected in both cytoplasm and nucleus. Amongst $35 \mathrm{BPH}$ cases, $33(94.3 \%)$ were unstained and $2(5.7 \%)$ had weak cytoplasmic staining. Weak nuclear staining was observed in 7 (20\%) BPH cases, moderate and strong nuclear staining was observed in $5(14.2 \%)$ and $3(8.57 \%)$ respectively, and $20(57.1 \%)$ were unstained. Among 70 adenocarcinomas, $67(96 \%)$ showed positively stained cytoplasm, of which $18(26 \%)$ stained weakly, $39(56 \%)$ stained moderately and $10(14 \%)$ stained strongly. Nuclear staining was negative in $11(16 \%)$, weakly positive in $14(20 \%)$, moderately positive in $22(31 \%)$ and strongly positive in $23(33 \%)$ carcinomas. The intensities of both cytoplasmic $\left(\chi^{2}\right.$ test, $\left.\mathrm{p}<0.001\right)$ and nuclear $\left(\chi^{2}\right.$ test, $\left.\mathrm{p}<0.001\right) \mathrm{C}-\mathrm{FABP}$ staining in carcinomas were significantly higher than those observed in normal and BPH cases. Some representative stains are shown in Fig. 1.

Correlation of $C-F A B P$ expression to $G S$. To correlate the intensity of C-FABP expression and GS, carcinomas were divided into low ( $\leq 5)$, moderate (6-7) and high (8-10) GS groups. The C-FABP expression status in the 3 groups of carcinomas is shown in Table I. The increased cytoplasmic staining intensities of C-FABP were significantly correlated with the increased GS of the carcinomas (2-sided Fisher's exact test, $\mathrm{p}<0.001)$ but the correlation between the increased nuclear staining intensities and the increased GS was not significant (2-sided Fisher's exact test, $\mathrm{p}>0.5$ ).

Relationship between patient survival and C-FABP expression. The relationship between C-FABP expression and length of patient survival time was assessed by Kaplan-Meier survival analysis. The relationship between the cumulative probability of surviving (survival time following initial diagnosis) and C-FABP expression is shown in Fig. 2A (cytoplasmic) and B (nuclear). The median survival time for the patients with negative and weakly cytoplasmic C-FABP staining (group 1) was 80 months; whereas the median survival time for the patients with moderate and strong cytoplasmic C-FABP staining (group 2) was significantly reduced to 36 months (log-rank test, $\mathrm{p}=0.003$ ). The median survival time for cases 
A

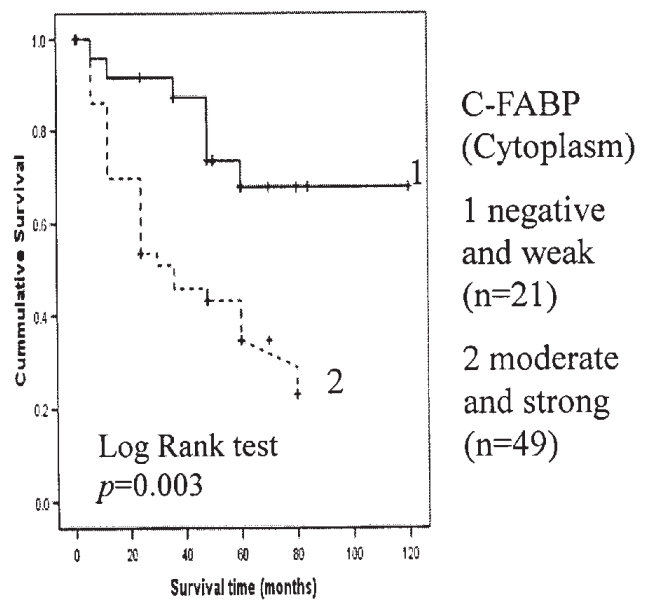

$\mathrm{B}$

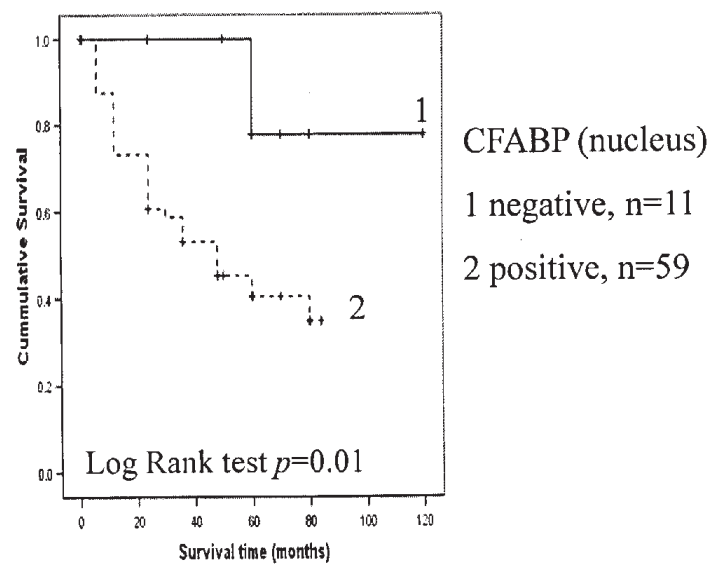

Figure 2. Kaplan-Meier survival curves of prostate cancer patients. A, Different levels of cytoplasmic expression of C-FABP: group 1, negative and weakly positive C-FABP stains ( $\mathrm{n}=21$ ); group 2, moderately and strongly positive C-FABP stains ( $\mathrm{n}=49$ ). B, Different levels of nuclear expression of C-FABP: group 1, negative C-FABP stains ( $\mathrm{n}=11$ ); group 2, positive C-FABP stains $(\mathrm{n}=59)$.

A

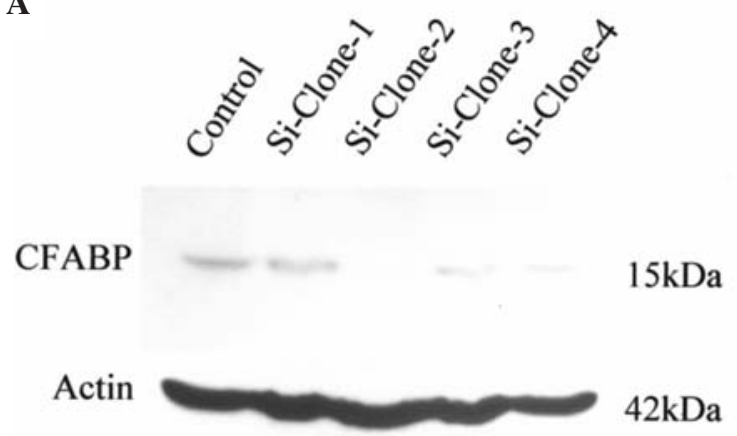

B

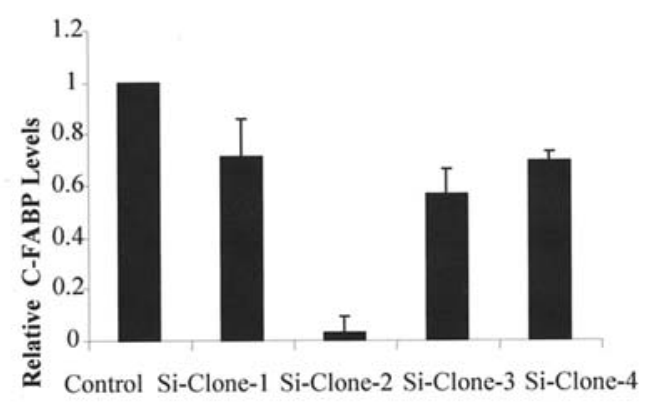

Cell Lines

Figure 3. Measurement of levels of C-FABP expressed in control and in different siRNA transfectant cell clones. A, Detection of C-FABP in control cells and in siRNA transfectant clones 1-4. Protein samples were extracted from each cell line and subjected to SDS-PAGE in $10 \%$ (w/v) polyarylamide gels. The separated proteins were transferred onto a nitrocellulose membrane by Western blotting. The membrane was firstly incubated with rabbit anti-C-FABP serum, then with horseradish peroxidase (HRP)-conjugated swine anti-rabbit immunoglobulin. The bound peroxidase was detected by ECL Western blot reagent kit using a light emitting non-radioactive method. The membrane was exposed to Kodak XAR-5 film for 1 min. The membrane was re-probed with constitutively expressed actin to standardise the amount of proteins loaded in each sample (the time for exposure to the film was $20 \mathrm{sec}$ ). B, Relative levels of C-FABP expressed in different cell lines. The level of C-FABP in control cells was set at 1.0, and the C-FABP levels in the siRNA transfectant clones were calculated by relating to the level detected in the control. The possible loading errors were corrected by normalizing values to $\beta$-actin, and the results are shown as the mean ( \pm SE) of three separate measurements.

with no nuclear staining (group 1) was 80 months, compared to a significantly (log-rank test, $\mathrm{p}=0.01$ ) reduced 48 months in cases with positive nuclear staining (group 2).

\section{$C$-FABP expression in control and different Si-transfectant} clones. The results of Western blot analysis of C-FABP expression in the control transfectants, which were generated by transfecting the parental PC-3M cells with plasmid DNA alone, and in 4 different Si-transfectant clones are shown in Fig. 3A. Further quantitative analysis of the relative levels of C-FABP expression in the control cells and in different Si-transfectant clones is shown in Fig. 3B. When the level of C-FABP expressed in the control tansfectants was set at 1 , the levels of C-FABP expression in all transfectant clones (Si-clone-1-4) were reduced to 0.71 (Si-clone-1), 0.032 ( $\mathrm{Si}$ - clone-2), 0.56 (Si-clone-3) and 0.69 (Si-clone-4) respectively. $\mathrm{Si}$-clone-2 was identified as the least C-FABP expressor, in which the siRNA produced a 31 -fold reduction in level of C-FABP when compared to the control.

The effect of siRNA on cell proliferation. The proliferation rates of the control and $\mathrm{Si}$-clone- 2 to 4 transfectant cells measured by proliferation assay are shown in Fig. 4A. After the same numbers $\left(1 \times 10^{3}\right)$ of cells from each cell line were cultured in separate plates for 6 days, the number of cells from each of the $3 \mathrm{Si}$-clones (2-4) was 35,000 \pm 5000 , $59,000 \pm 6,000$, and $68,000 \pm 5,000$, respectively. In contrast the number of cells derived from the control transfectants was $102,900 \pm 13,000$. In comparison with the control cells, the number of Si-clone-2 cells was significantly (Student's 


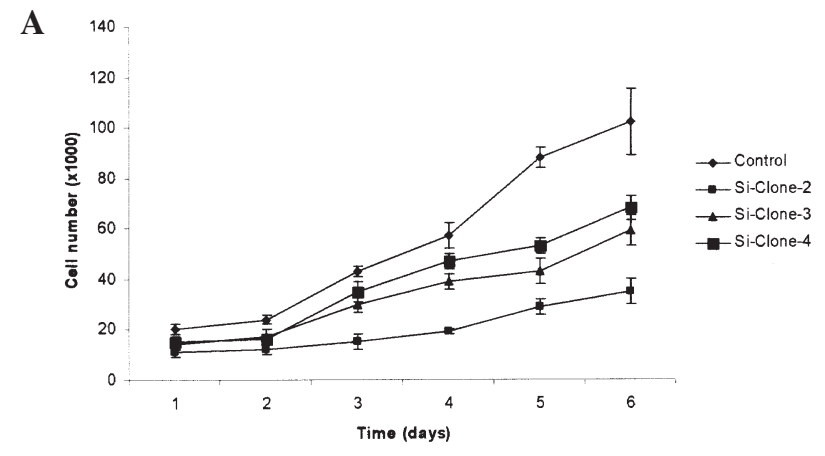

B 250

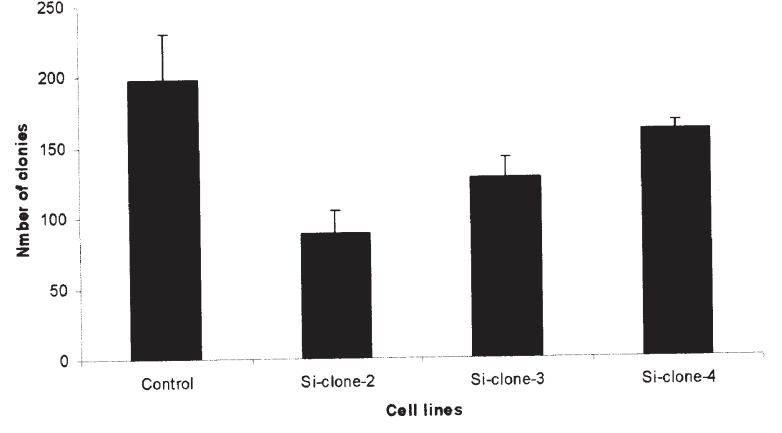

Figure 4. Proliferation rate and in vitro tumourigenicity of control cells and the siRNA transfectant Si-clone- 2 to 4 cells. A, The effects of suppressed C-FABP expression on cellular proliferation. The cells from Si-clone-2, Si-clone-3, Si-clone-4, and the control transfectants were cultured respectively for 6 days and measurements taken every day to measure the cell numbers. Results shown are the mean cell numbers $( \pm \mathrm{SE})$ of 3 separate measurements. $\mathrm{B}$, The effect of suppressed C-FABP expression on the ability of colony formation in soft agar assays. Cells $\left(5 \times 10^{3}\right)$ from different Si-clones and from the control transfectants were plated respectively in triplicate in 6-well dishes to test their tumourigenicity in agarose gel. Quantitative assessment of tumourigenicity of different Si-clone cells and the control transfectant cells was made by calculating the number of colonies formed in soft agar. The numbers of colonies are shown by the mean $( \pm S E)$ of three separate experiments.

t-test, $\mathrm{p}<0.03$ ) reduced by 2.9-times; numbers of Si-clone-3 cells and Si-clone-4 cells were reduced 1.7- and 1.5-fold, respectively, although these reductions were not statistically significant.

Analysis of tumourigenicity by soft agar assay in vitro. The tumourigenicity of Si-clones-2-4 and the control cells was assessed by their ability to form colonies in soft agar (Fig. 4B).
After an equal number of cells from the control and each of the Si-clones were cultured within a soft agar matrix over a period of 6 weeks, the control cells produced $198 \pm 32$ colonies in soft agar, whereas the Si-clone-2 cells produced only $88 \pm 17$ colonies, a significant (Student's t-test, $\mathrm{p}<0.005$ ) reduction of 2.3 -fold. In comparison with the control cells, the number of colonies produced by $\mathrm{Si}$-clone- 3 cells was significantly (Student's t-test, $\mathrm{p}<0.03$ ) reduced to $127 \pm 15$ and that produced by $\mathrm{Si}$-clone- 4 was reduced to $161 \pm 6$ which was not statistically significant.

Tumourigenicity and metastasis assay in nude mouse. The tumourigenicity and metastatic capability of the control and the Si-clone-2 cells implanted orthortopically into the mouse prostate gland are shown in Table II. Each of the 2 cell lines was inoculated in 14 animals. But 1 mouse in the test group (inoculated with Si-clone-2 cells) suffered post-operational complications and was excluded from this experiment. Thirteen out of $14(93 \%)$ mice implanted with control transfectant cells produced primary tumours, whereas only 2 of the 13 (15\%) mice implanted with Si-clone-2 cells produced primary tumours, a significant (Fisher's exact test, $\mathrm{p}<0.02$ ) reduction from control. The average size of tumours produced by control cells was $1450 \pm 37 \mathrm{mg}$. This was significantly (Student's t-test, $\mathrm{p}<0.0001$ ) reduced to only $23 \pm 5 \mathrm{mg}$ produced by Si-clone- 2 cells. Nine of the 14 mice implanted with control transfectants developed metastases and all were found in the lungs. Seven metastases were micro-lesions and 2 were macroscopically visible. Histological examination revealed a haematogenous route of spread of the malignant cells (Fig. 5A). No metastasis was produced in any of the mice implanted with Si-clone-2 cells. Immunohistological staining showed that C-FABP was strongly expressed in both primary tumours and metastases produced by the control cells. It was also strongly expressed in primary tumours produced by Si-clone-2 cells (Fig. 5B).

To test whether the suppression of tumour development in Si-clone- 2 cells occurred in the initiation stage or in the maintenance stage, the control and Si-clone- 2 cells were subcutaneously inoculated into 2 groups (5 each) of mice. The average volume of tumours produced by 2 groups of animals over a 5-week period is shown in Fig. 6. All 5 mice $(100 \%)$ inoculated with control cells developed visible tumours after a 4-day latent period. When the animals were sacrificed 5 weeks after inoculation, the mean volume of the 5 tumours

Table II. Incidence of primary tumours and metastases produced by the control and the Si-clone-2 implanted orthotopically into the prostate gland of nude mice.

\begin{tabular}{lcccc}
\hline Cell line & Surgical procedures $^{\mathrm{a}}$ & ${\text { Tumour incidence }(\%)^{\mathrm{b}}}$ & ${\text { Mean tumour mass }(\mathrm{mg})^{\mathrm{c}}}^{\text {Metastasis incidence }^{\mathrm{d}}}$ \\
\hline Control & Orthotopic implantation & $13 / 14(93)$ & $1450 \pm 370$ & $9 / 14(64 \%)$ \\
Si-Clone-2 & Orthotopic implantation & $2 / 13(15)$ & $23 \pm 5$ & $0 / 13 \quad(0 \%)$ \\
\hline
\end{tabular}

${ }^{a}$ One mouse in the Si-clone-2 group suffered post-operative complications and was excluded from the study. ${ }^{\mathrm{b}}$ Tumour incidence was defined

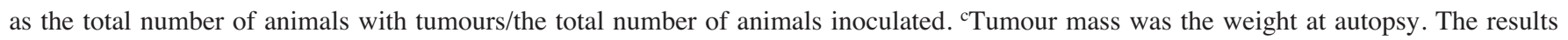
shown are the mean $( \pm \mathrm{SE})$ of each group. ${ }^{\mathrm{d}}$ Incidence of metastases was defined as the total number of mice with metastasis/the total number of animals inoculated. 
A

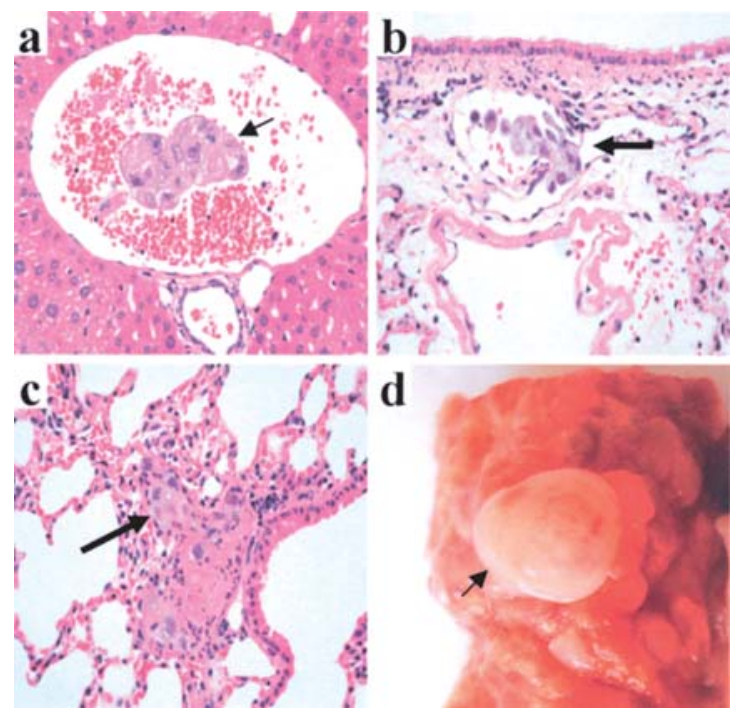

B

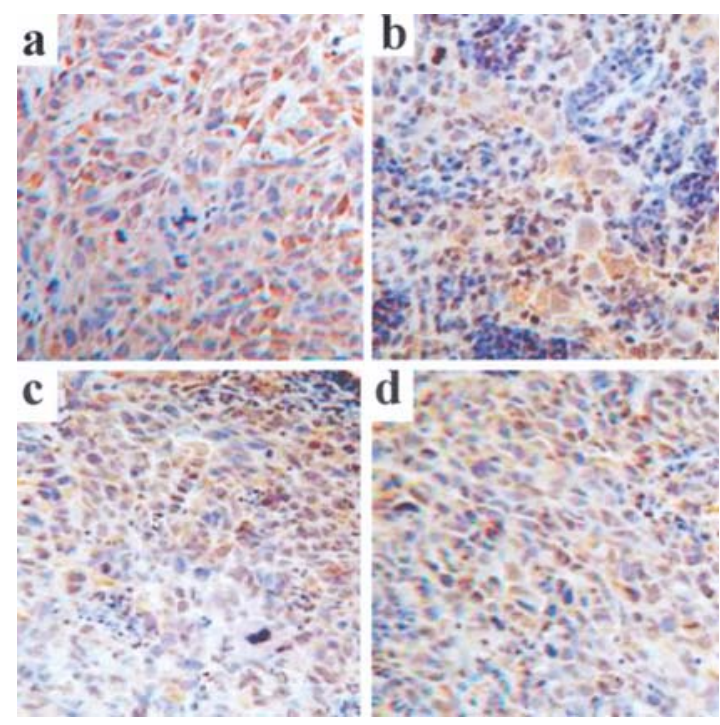

Figure 5. Malignant dissemination of the cancer cells and C-FABP expression in primary tumour and metastasis. A, Metastasis-forming process of the control cells in nude mouse. a, Haematoxylin and eosin staining of a liver tissue showing the presence of a cluster of tumour cells (originating from the control cells) in a blood vessel. b, A cluster of tumour cells across the blood vessel membrane (extravasation) and invading into the lung tissue. c, A micro-metastasis was established in lung tissue. D, A photograph of a fully established lung metastasis. B, Immunohistochemical detection of C-FABP expression in primary tumour and metastasis. a, Strongly positive staining in a primary tumour produced by the control cells. b, Strongly positive staining in a lung metastasis produced by the control cells. $\mathrm{c}$ and d, Strongly positive staining in both primary tumours produced by Si-transfectant clone- 2 cells.

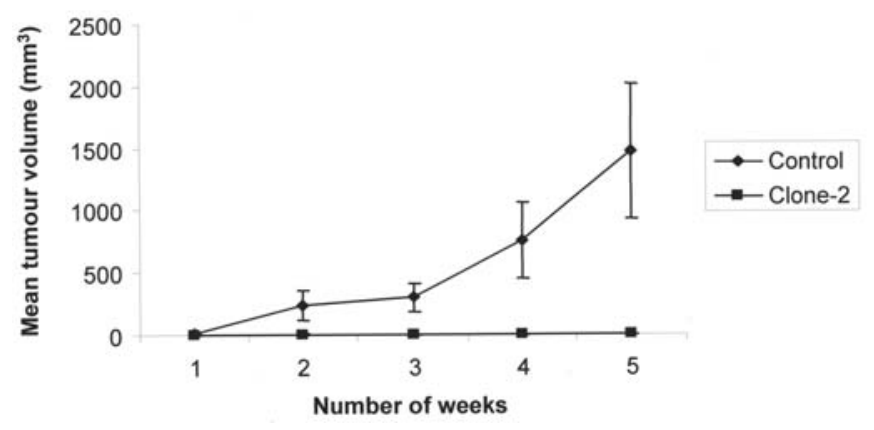

Figure 6. Tumour volumes produced by Si-clone-2 cells and the control cells. The Si-Clone-2 cells and the control cells were inoculated subcutaneously into two groups (5 each) of male immuno-compromised $\mathrm{CD} / 1$ nude mice by subcutaneous injection in the shoulder region. The tumour sizes were measured weekly for 5 weeks after the inoculation and tumour volumes were calculated using the formulae $\mathrm{V}=\mathrm{L} \times \mathrm{H} \times \mathrm{W} \times 0.5237$ (29). The results shown are the mean tumour volumes $( \pm \mathrm{SE})$ of five animals.

was $1471 \pm 997 \mathrm{~mm}^{3}$. In the group of mice inoculated with Si-clone- 2 cells, none of the animals $(0 \%)$ developed tumours. The tumour incidence in this group of mice was significantly (Student's t-test, $\mathrm{p}<0.025$ ) lower than that in the control group.

\section{Discussion}

C-FABP is a $15-\mathrm{kDa}$ cytosolic protein of the fatty acid binding protein family (12), which binds with high affinity to long chain fatty acids. C-FABP expression, in addition to skin, has been identified in the endothelial cells of the placenta, heart, skeletal muscle, small intestine, renal medulla and in the Clara and goblet cells of the lung (30), and also in malignancies of the bladder and pancreas (31-33). Although the molecular mechanism by which increased C-FABP activity functions within these tissues is unclear, its ability to bind and transport fatty acids may be of importance in the malignant transformation of some cancer cells. Our previous work, has found that the C-FABP gene was overexpressed in malignant breast and prostate epithelial cell lines. When C-FABP gene was transfected into the benign rat Rama 37 model cells $(24,25)$ and the transfectants subsequently inoculated into Wistar Furth rats (Wistar OLA strain), a significant number of animals developed metastasis (11). Further studies demonstrated that C-FABP promoted tumourigenesis and metastasis of prostate cancer cells by facilitating angiogenesis through up-regulating VEGF gene $(34,35)$. Thus it was suggested that there may be a fatty acid signallinginitiated pathway that leads to metastasis in prostate cancer, and C-FABP, VEGF, and the peroxisome proliferatoractivated receptor (PPAR) $-\gamma$ (36) are all important factors in the this possible pathway $(14,15)$.

Although over-expression of C-FABP and its involvement in malignant progression of prostate cancer and other cancers has been reported $(14,32,33,37,38)$, its possible prognostic significance and usefulness as a therapeutic target were not investigated. In order to study the clinical relevance of the elevated C-FABP expression in prostate cancer, we examined the expression status of C-FABP in an archival set of prostate cancer tissues. It was found that only $5.7 \%$ of the BPH samples expressed C-FABP, whereas in carcinomas, $96 \%$ of the tissues expressed C-FABP (Table I). Although there was no significant correlation between the increased nuclear C-FABP staining and the increased GS, the increased cytoplasmic intensities of C-FABP staining were significantly correlated with the increased GS of the carcinomas (2-sided Fisher's exact test, $\mathrm{p}<0.001)$, indicating that the increased C-FABP expression in cytoplasm might contribute to an increased 
degree of malignancy. The median survival time for the patients with moderate and strong cytoplasmic C-FABP staining was 36 months, whereas for the patients with negative and weakly cytoplasmic C-FABP staining the median survival time was 80 months (Fig. 2A). Thus, the increased C-FABP in cytoplasm was significantly associated with a 2.2-fold reduction in patient survival (log-rank test, $\mathrm{p}=0.003$ ). The median survival time for cases with no nuclear C-FABP staining was 80 months, whereas that for cases with positive nuclear stains was 48 months, a significant reduction of 1.7 times (log-rank test, $\mathrm{p}=0.01$ ). The median survival time was 120 months for the cases in which C-FABP expression in cytoplasm and nucleus jointly was weak or absent; reduced to 80 months for the cases expressing moderate levels of $\mathrm{C}-\mathrm{FABP}$ in either cytoplasm or nucleus; and further highly significantly (log-rank test, $\mathrm{p}<0.0001$ ) reduced to 24 months for cases strongly expressing C-FABP. These results suggested that the increased C-FABP in cytoplasm and nucleus, either separately or jointly, was significantly associated with a reduced patient survival time. Therefore, an increased C-FABP expression in prostate cancer may be new prognostic factor for prediction of patient outcome.

To explore the possibility of using C-FABP expression as a target to inhibit the malignant progression of prostate cancer cells, we have successfully suppressed the C-FABP expression in the highly malignant, metastatic prostate cancer cell line PC-3M and generated a transfectant clone (Si-clone-2), in which the level of C-FABP was suppressed by 31-fold. In addition several more clones producing moderately-reduced levels of C-FABP were also established. When tested by a proliferation assay for 6 days, Si-clone- 2 cells exhibited a significantly lower (by 2.5-fold) proliferation rate (Fig. 4A). Si-clone-3 and Si-clone-4, which expressed 0.56- and 0.69times of the amount of C-FABP than in control, exhibited lower (by 1.7- and 1.5-fold, respectively) proliferation rates. These results suggested a trend for reduced proliferation to be associated with greater inhibition of C-FABP expression. A similar trend was also observed in soft agar assays. Thus, while the control cells expressed 31-, 1.8- and 1.5-fold more $\mathrm{C}-\mathrm{FABP}$ respectively than Si-clone 2 to 4 cells, they produced 2.3-, 1.5- and 1.2-times the number of colonies (Fig. 4B). Thus, suppression of C-FABP expression in highly malignant prostate cancer cells in vitro greatly inhibits their proliferation rate and tumourigenicity.

When the control and the Si-clone-2 cells were implanted orthortopically into the mouse prostate gland, 13/14 (93\%) mice in the control group produced primary tumours, whereas only 2 of the $13(15 \%)$ mice implanted with Siclone-2 cells produced primary tumours, a significant (Fisher's exact test, $\mathrm{p}<0.02$ ) 6.2-fold reduction in tumour incidence. The average size of the tumours produced by the control cells was $1450 \pm 37 \mathrm{mg}$, compared with $23 \pm 5 \mathrm{mg}$ produced by $\mathrm{Si}$-clone- 2 cells, a significant (Student's t-test, $\mathrm{p}<0.0001$ ) 63-fold reduction (Table II). Thus, suppressing the expression of C-FABP in PC-3M cells significantly reduced both the incidence and average size of tumours growing in the primary inoculation site. Further analysis showed that $9 / 14(64 \%)$ mice implanted with control transfectants produced metastases, whereas no metastasis occurred in any of the mice implanted with Si-clone- 2 cells.
The role of C-FABP as a promoter of the development of both primary tumours and metastasis was confirmed by our observation of strong immunoexpression in both primary tumours and metastases derived from control cells (Fig. 5B).

All 5 mice $(100 \%)$ inoculated subcutaneously with control cells developed visible tumours after a 4-day latent period. When the animals were sacrificed 5 weeks after inoculation, the mean volume of the 5 tumours was $1471 \pm 997 \mathrm{~mm}^{3}$, whereas no tumours developed in any of the 5 animals inoculated subcutaneously with the control cells. This result suggested that the suppression of tumour development in Si-clone- 2 cells occurred in the initiation stage by preventing the cells from forming primary tumours. Interestingly, CFABP was expressed in the 2 small primary tumours produced by Si-clone-2 (Fig. 5B). This result combined with subcutaneous inoculation experiment results indicated that the development of these 2 tumours might be consequences of de-suppression of C-FABP in Si-clone-2 cells. During the in vivo inoculation, it might be possible that some changes occurred to the mechanism, by which the RNAi-suppressed the expression of C-FABP, and as a result of these yet unknown changes, the suppression mechanism was loosen and the expression of C-FABP was recovered in the cancer cells, and hence the tumours developed.

An increased activity of the cancer-promoting genes is one of the major factors involved in the development and spread of the cancer cells. The increased expression of these cancer-promoting genes provides a valuable pool of candidates, from which reliable prognostic markers may be selected (38). Furthermore, suppression of the expression of cancerpromoting genes may provide an effective way to stop or to reverse malignant progression (40-42). However, the success of the strategies for targeting metastasis-promoting genes will first depend on the identification, verification and determination of reliable targets. In this work, we have assessed whether C-FABP maybe such a target. Our results show that an increased C-FABP expression is significantly associated with the early demise of prostate cancer patients, whereas suppressing the expression of C-FABP in prostate cancer cells results in a highly significant reduction in tumourigenicity and complete inhibition of metastasis. These finding suggest that increased expression of C-FABP maybe a valuable prognostic factor predicting the outcome in prostate cancer patients, and it may also prove to be an important target for designing effective strategies to treat the disease.

\section{Acknowledgements}

We thank North West Cancer Research Fund for its generous support of research grant.

\section{References}

1. Jemal A, Murray T, Ward E, Samuels A, Tiwari RC, Ghafoor A, Feuer EJ and Thun MJ: Cancer statistics. CA Cancer J Clin 55: 10-30, 2005.

2. Landis SH, Murray T, Bolden S and Wingo PA: Cancer Statistics. CA Cancer J Clin 49: 8-31, 1999.

3. Foster CS, Cornford P, Forsyth L, Djamgoz MB and Ke Y: The cellular and molecular basis of prostate cancer. BJU Int 83: 171-194, 1999.

4. Liang P and Pardee AB: Analysing differential gene expression in cancer. Nat Rev 3: 869-876, 2003 
5. Liang $\mathrm{P}$ and Pardee AB: Differential display of eukaryotic messenger RNA by means of the polymerase chain reaction. Science 257: 967-971, 1992.

6. Jing C, Rudland PS, Foster CS and Ke Y: Microquantity differential display: a strategy for a systematic analysis of differential gene expression with a small quantity of starting RNA. Anal Biochem 287: 334-337, 2000.

7. Ke Y, Jing C, Rudland PS, Smith P and Foster CS: Systematic comparison of gene expression through analysis of cDNA fragments within or near to the protein-coding region. Nucleic Acids Res 27: 912-914, 1999.

8. Ke Y, Rudland PS, Jib C, Smith P and Foster CS: Systematic differential display: a strategy for a complete assessment of differential gene expression. Anal Biochem 269: 201-204, 1999.

9. Bee A, Ke Y, Forootan S, Lin K, Beesley C, Forrest SE and Foster CS: Ribosomal protein 119 is a prognostic marker for human prostate cancer. Clin Cancer Res 12: 2061-2065, 2006.

10. Jing C, El-Ghany MA, Beesley C, Foster CS, Rudland PS, Smith P and Ke Y: Tazarotene-induced gene 1 (TIG1) expression in prostate carcinomas and its relationship to tumorigenicity. $\mathrm{J}$ Natl Cancer Inst 94: 482-490, 2002.

11. Jing C, Beesley C, Foster CS, Rudland PS, Fujii H, Ono T, Chen $\mathrm{H}$, Smith PH and Ke Y: Identification of the messenger RNA for human cutaneous fatty acid-binding protein as a metastasis inducer. Cancer Res 60: 2390-2398, 2000.

12. Madsen P, Rasmussen HH, Leffers H, Honore B and Celis JE: Molecular-cloning and expression of a novel keratinocyte protein (psoriasis-associated fatty-acid binding-protein [pa-fabp]) that is highly up-regulated in psoriatic skin and that shares similarity to fatty-acid binding proteins. J Invest Dermatol 99: 299-305, 1992.

13. Dunnington DJ, Hughes CM, Monaghan P and Rudland PS: Phenotypic instability of rat mammary tumor epithelial cells. J Natl Cancer Inst 71: 1227-1240, 1983.

14. Adamson J, Morgan EA, Beesley C, Mei Y, Foster CS, Fujii H, Rudland PS, Smith P and Ke Y: High-level expression of cutaneous fatty acid-binding protein in prostatic carcinomas and its effect on tumorigenicity. Oncogene 22: 2739-2749, 2003.

15. Jing C, Beesley C, Foster CS, Chen H, Rudland PS, West DC, Fujii H, Smith P and Ke Y: Human cutaneous fatty acid-binding protein induces metastasis by up-regulating the expression of vascular endothelial growth factor gene in rat Rama 37 model cells. Cancer Res 61: 4357-4364, 2001.

16. Chen HJ, Treweeke AT, Ke YQ, West DC and Toh CH: Angiogenically active vascular endothelial growth factor is overexpressed in malignant human and rat prostate carcinoma cells. Br J Cancer 82: 1694-1701, 2000.

17. Kozlowski JM, Fidler IJ, Campbell D, Xu ZL, Kaighn ME and Hart IR: Metastatic behavior of human tumor cell lines grown in the nude mouse. Cancer Res 44: 3522-3529, 1984.

18. Brummelkamp TR, Bernards R and Agami R: A system for stable expression of short interfering RNAs in mammalian cells. Science 296: 550-553, 2002.

19. Elbashir SM, Harborth J, Lendeckel W, Yalcin A, Weber K and Tuschl T: Duplexes of 21-nucleotide RNAs mediate RNA interference in cultured mammalian cells. Nature 411: 494-498, 2001.

20. Gleason DF and Mellinger GT: Prediction of prognosis for prostatic adenocarcinoma by combined histological grading and clinical staging. J Urol 111: 58-64, 1974.

21. Foster CS, Gosden CM and Ke YQ: Primer: tissue fixation and preservation for optimal molecular analysis of urologic tissues. Nat Clin Pract 3: 268-278, 2006.

22. Forootan SS, Foster CS, Aachi VR, Adamson J, Smith PH, Lin K and $\mathrm{Ke} \mathrm{Y}$ : Prognostic significance of osteopontin expression in human prostate cancer. Int J Cancer 118: 2255-2261, 2006.

23. Kaighn ME, Lechner JF, Narayan KS and Jones LW: Prostate carcinoma: tissue culture cell lines. Natl Cancer Inst Monogr pp17-21, 1978.

24. Ke Y, Beesley C, Smith P, Barraclough R, Rudland P and Foster CS: Generation of metastatic variants by transfection of a rat non-metastatic epithelial cell line with genomic DNA from rat prostatic carcinoma cells. Br J Cancer 77: 287-296, 1998.
25. Chen H, Ke Y, Oates AJ, Barraclough R and Rudland PS: Isolation of and effector for metastasis-inducing DNAs from a human metastatic carcinoma cell line. Oncogene 14: 1581-1588, 1997.

26. Ke Y, Jing C, Barraclough R, Smith P, Davies MP and Foster C: Elevated expression of calcium-binding protein $\mathrm{p} 9 \mathrm{Ka}$ is associated with increasing malignant characteristics of rat prostate carcinoma cells. Int J Cancer 71: 832-837, 1997.

27. Chien J, Wong E, Nikes E, Noble MJ, Pantazis CG and Shah GV: Constitutive activation of stimulatory guanine nucleotide binding protein $[\mathrm{G}(\mathrm{S})$ alphaQL]-mediated signaling increases invasiveness and tumorigenicity of PC-3M prostate cancer cells. Oncogene 18: 3376-3382, 1999.

28. Rembrink K, Romijn JC, van der Kwast TH, Rubben H and Schroder FH: Orthotopic implantation of human prostate cancer cell lines: a clinically relevant animal model for metastatic prostate cancer. Prostate 31: 168-174, 1997.

29. Janik P, Briand P and Hartmann NR: The effect of estroneprogesterone treatment on cell proliferation kinetics of hormonedependent GR mouse mammary tumors. Cancer Res 35: 3698-3704, 1975.

30. Masouye I, Saurat JH and Siegenthaler G: Epidermal fattyacid-binding protein in psoriasis, basal and squamous cell carcinomas: an immunohistological study. Dermatology 192: 208-213, 1996.

31. Celis A, Rasmussen HH, Celis P, Basse B, Lauridsen JB, Ratz G, Hein B, Ostergaard M, Wolf H, Orntoft T and Celis JE: Shortterm culturing of low-grade superficial bladder transitional cell carcinomas leads to changes in the expression levels of several proteins involved in key cellular activities. Electrophoresis 20: 355-361, 1999.

32. Ostergaard M, Rasmussen HH, Nielsen HV, Vorum H, Orntoft TF, Wolf H anf Celis JE: Proteome profiling of bladder squamous cell carcinomas: identification of markers that define their degree of differentiation. Cancer Res 57: 4111-41117, 1997.

33. Sinha P, Hutter G, Kottgen E, Dietel M, Schadendorf D and Lage $\mathrm{H}$ : Increased expression of epidermal fatty acid binding protein, cofilin, and 14-3-3-sigma (stratifin) detected by twodimensional gel electrophoresis, mass spectrometry and microsequencing of drug-resistant human adenocarcinoma of the pancreas. Electrophoresis 20: 2952-2960, 1999.

34. Jackson MW, Roberts JS, Heckford SE, Ricciardelli C, Stahl J, Choong C, Horsfall DJ and Tilley WD: A potential autocrine role for vascular endothelial growth factor in prostate cancer. Cancer Res 62: 854-859, 2002.

35. Soker S, Kaefer M, Johnson M, Klagsbrun M, Atala A and Freeman MR: Vascular endothelial growth factor-mediated autocrine stimulation of prostate tumor cells coincides with progression to a malignant phenotype. Am J Pathol 159: 651-659, 2001

36. Xu HE, Lambert MH, Montana VG, Parks DJ, Blanchard SG, Brown PJ, Sternbach DD, Lehmann JM, Wisely GB, Willson TM, Kliewer SA and Milburn MV: Molecular recognition of fatty acids by peroxisome proliferator-activated receptors. Mol Cell 3: 397-403, 1999

37. Fujii K, Kondo T, Yokoo H, Yamada T, Iwatsuki K and Hirohashi S: Proteomic study of human hepatocellular carcinoma using two-dimensional difference gel electrophoresis with saturation cysteine dye. Proteomics 5: 1411-1422, 2005.

38. Munz M, Zeidler R and Gires O: The tumour-associated antigen EpCAM upregulates the fatty acid binding protein E-FABP. Cancer Lett 225: 151-157, 2005.

39. Sidransky D: Emerging molecular markers of cancer. Nature Rev 2: 210-219, 2002.

40. Felsher DW: Cancer revoked: oncogenes as therapeutic targets. Nat Rev Cancer 3: 375-380, 2003.

41. Foley R, Lawler M and Hollywood D: Gene-based therapy in prostate cancer. Lancet Oncol 5: 469-479, 2004.

42. Borghouts C, Kunz C and Groner B: Current strategies for the development of peptide-based anti-cancer therapeutics. J Pept Sci 11: 713-726, 2005. 